Dear Author,

Please, note that changes made to the HTML content will be added to the article before publication, but are not reflected in this PDF.

Note also that this file should not be used for submitting corrections. 
Research paper

\section{On the interest of using the multiple center approach in ESR dating of optically bleached quartz grains: Some examples from the Early Pleistocene terraces of the Alcanadre River (Ebro basin, Spain)}

Q9 Duval Mathieu ${ }^{\mathrm{a}, \mathrm{b},{ }^{*} \text {, Sancho Carlos }}{ }^{\mathrm{c}}$, Calle Mikel ${ }^{\mathrm{d}}$, Guilarte Verónica a José Luis Peña-Monné ${ }^{e}$

a Program of Geochronology, Centro nacional de investigación sobre la evolución humana (CENIEH), Burgos, Spain

${ }^{\mathrm{b}}$ Research School of Earth Sciences, The Australian National University, Canberra, Australia

c Ciencias de la Tierra, Universidad de Zaragoza, Pedro Cerbuna 12, 50009 Zaragoza, Spain

${ }^{\mathrm{d}}$ National Museum of Natural Sciences (MNCN), CSIC, Madrid, Spain

e Geografia y Ordenación del Territorio, Universidad de Zaragoza, Pedro Cerbuna 12, 50009 Zaragoza, Spain

\section{A R T I C L E I N F O}

Article history:

Received 9 January 2015

Received in revised form

1 June 2015

Accepted 3 June 2015

Available online $\mathrm{xxx}$

\section{Keywords:}

Quaternary geochronology

Electron spin resonance dating

Optically bleached quartz grains

Fluvial deposits

Terraces

Alcanadre river

Ebro basin

\begin{abstract}
A B S T R A C T
The present work reports the first numerical ages obtained for two highest fluvial terraces (Qt1 and Qt2) of the Alcanadre River system (Northeastern Spain) representing the earliest remnants of Quaternary morphosedimentary fluvial activity in the Ebro basin. ESR dating method was applied to optically bleached quartz grains and both the $\mathrm{Al}$ and Ti centers were measured, in accordance with the Multiple Center approach. The results are overall in good agreement with the existing preliminary chronostratigraphic framework and our interpretation indicate that terraces Qt1 and Qt2 have an ESR age of $1276 \pm 104 \mathrm{ka}$ and $817 \pm 68 \mathrm{ka}$, respectively. These data provide some chronological insights on the beginning of the fluvial sedimentary processes in a scenario of incision maintained over Quaternary in the Ebro Basin. These are among the first numerical ages obtained for such high terraces in the Iberian Peninsula.

Our results demonstrate the interest of using the Multiple Center approach in ESR dating of quartz, since the two centers provide complementary information, i.e. an independent dose control. The overall apparent consistency between the ESR age estimates and the existing preliminary chronostratigraphic framework may be considered as an empirical evidence that the Ti-Li center may actually work for Early Pleistocene deposits, whereas the $\mathrm{Ti}-\mathrm{H}$ center shows some clear limitations instead. Finally, these results demonstrate the interest of using ESR method to date Early Pleistocene fluvial terraces that are usually beyond the time range covered by the OSL dating method.
\end{abstract}

๑) 2015 Published by Elsevier B.V.

\section{Introduction}

Fluvial terrace sequences are known to be valuable Quaternary continental archives that can record regional paleoclimatic, palaeoenvironmental or paleogeographic fluctuations (e.g. Bridgland et al., 2004; Bridgland and Westaway, 2008), markers of longterm landscape development (e.g. Wegmann and Pazzaglia, 2009; Westaway et al., 2009) and evidence of prehistoric hominid occupations (see a review in Mishra et al., 2007). This is why

* Corresponding author. Program of Geochronology, Centro nacional de inves- establishing accurate chronologies of these deposits has always been of crucial importance (e.g. Hosfield and Chambers, 2005; Bidgland et al., 2004). Many tools are available for this purpose. For example, if paleontological remains have been preserved in the sediment and may be identified, biostratigraphy may rapidly give a first overview of the chronological framework. Then, provided that the sedimentary context is suitable for palaeomagnetic studies, which is not systematic in presence of coarse deposits (Tauxe, 2010), further age constraint may be obtained in case some geomagnetic polarity reversals may be identified. However, as soon as higher chronological resolution is required, these data must be complemented with numerical ages. A wide range of dating methods is potentially available in that regard, but their use actually depends on several factors, such as the nature of the

E-mail address: mathieu.duval@cenieh.es (D. Mathieu).

http://dx.doi.org/10.1016/j.quageo.2015.06.006
1871-1014/@ 2015 Published by Elsevier B.V. 
sedimentary environment, the material that may be found within the deposits, as well as the age of these deposits. This is why some reference radiometric methods like radiocarbon, U-series or Argon-Argon may be punctually very useful to provide highprecision ages (e.g. Bridgland et al., 2004; Sharp et al., 2003; Schulte et al., 2008; Pan et al., 2003), but their application to fluvial terraces remains nevertheless overall somewhat limited. In contrast, other numerical methods like Terrestrial Cosmogenic Nuclides (TCN), Optically Stimulated Luminescence (OSL) or Electron Spin Resonance (ESR) that are based on minerals that are commonly found in fluvial environment, such as silicates and particularly quartz, offer perhaps a greater potential in this specific context.

Actually, Electron Spin Resonance (ESR) and Optically Stimulated Luminescence (OSL) dating methods can be both applied to optically bleached quartz grains to date the same event, i.e. when the sediment has been last exposed to sunlight. These two palaeodosimetric or trapped charge dating methods are based on the same principles, i.e. the study of the effect of the natural radioactivity on materials, which is quantified in terms of radiation absorbed dose values. To do so, they focus on radiation-induced signals by looking at either paramagnetic (ESR) or luminescent (OSL) properties of materials (see basic principles in Aitken, 1998; Ikeya, 1993). Actually, OSL is widely used to date Late Pleistocene to Holocene fluvial deposits, but the rapid saturation of the signal make that the standard dating approach can generally not go beyond $\sim 200 \mathrm{ka}$, depending mainly on the magnitude of the dose rate, which means that most of the Early to Middle Pleistocene terraces can simply not be dated with this technique (e.g. Schulte et al., 2008; Lewis et al., 2009; Martins et al., 2009). It is nevertheless worth mentioning that some new approaches have been recently developed to go further back in time (see a review in Arnold et al., 2014), but their use remains for the moment quite limited given the time required for data acquisition and reduction. In comparison with OSL signals, paramagnetic centers measured by ESR in quartz for geochronological purpose such as Aluminum (Al) or Titanium ( $\mathrm{Ti}$ ) centers have greater saturation levels with the dose (Duval, 2012; Duval and Guilarte, 2015), and have shown an interesting potential in fluvial context to date complete River terrace systems covering the whole Pleistocene time range (e.g. Voinchet et al., 2010). As shown by Cordier et al. (2012), it can actually offer a valuable alternative to the OSL method to refine the chronology of the oldest terraces of fluvial terraces systems that are frequently lacking of numerical ages. The Iberian Peninsula is an excellent example in that regard (see Santisteban and Schulte, 2007). However, perhaps the major challenge in ESR dating lies in evaluating whether the signal has been fully reset prior to sediment deposition, given that the $\mathrm{Al}$ center is known to have not only a somewhat slow bleaching kinetics but also an unbleachable (=residual) component of its ESR signal (e.g. Toyoda et al., 2000; Tissoux et al., 2007; Voinchet et al., 2003), in contrast with the Ti-center that is, however, more complicated to measure (e.g. Duval and Guilarte, 2015 and references therein). To address this issue, some authors proposed the combined analysis of both $\mathrm{Al}$ and $\mathrm{Ti}$ centers in quartz samples, the so-called multiple center approach (Toyoda et al., 2000), but its potential remains nevertheless to be better defined.

Actually, the Ebro Basin drainage (Notheastern Spain) is a typical example where the ESR dating method can be especially useful for constraining the chronology of the staircase fluvial terraces. Specifically, the Alcanadre River developed an extensive terrace sequence made of nine strath levels (Fig. 1) very suitable for numerical dating. OSL dating method was applied to the lowest terraces providing preliminary Late Pleistocene ages (for further details, see Calle, 2012; Calle et al., 2013). For the older terrace deposits, ongoing magnetostratigraphic studies indicate some inverse polarity intervals that may be correlated to the Matuyama chron ( $>0.78 \mathrm{Ma}$ ), suggesting thus an Early Pleistocene chronology. In particular, the oldest terrace of the Alcanadre River sequence (South Pyrenean piedmont) exhibits large preserved outcrops and includes interesting paleogeographical information, at regional scale, because representing the earliest mophosedimentary pulse under exoreic conditions (Alberto et al., 1983) after the opening of the Tertiary Ebro Basin toward the Mediterranean Sea between 13 and 8.5 Ma ago (GarcíaCastellanos et al., 2003).

In order to improve and refine the current chronostratigraphic framework, we collected four sediment samples from the two highest terraces of the Alcanadre River for ESR dating purpose, which was also an excellent opportunity to evaluate the potential of multiple center method for this specific time range.

\subsection{The multiple center (MC) approach: basic principles}

First suggested by Toyoda et al. (2000) after observing the large variability of the bleaching kinetics of various paramagnetic centers measured in quartz grains, this approach consists in measuring the ESR signals of both the Aluminum ( $\mathrm{Al}$ ) and Titanium (Ti) centers in a given sample in order to evaluate whether full bleaching of the $\mathrm{Al}$ center has been achieved prior to sediment deposition.

Actually, the signal of the Al center has been so far the most widely used for geochronological purpose since the pioneering work by Yokoyama et al. (1985). It has the main advantage to be observed in almost any quartz samples, and usually has an intensity that is high enough to ensure repeatable measurements (e.g. Duval and Guilarte Moreno, 2012), given that Aluminum $\left(\mathrm{Al}^{3+}\right)$, as a precursor of the $\mathrm{Al}$ paramagnetic center, is usually the most abundant impurity present in alpha quartz (Preusser et al., 2009). The ESR signal associated with the Al center is known to have a high thermal stability and radiation saturation level (e.g. Toyoda and Ikeya, 1991; Duval, 2012) so that it could be used to date Early Pleistocene materials (e.g. Rink et al., 2007; Duval et al., 2015), or even older (Laurent et al., 1998). However, its bleaching kinetics is quite slow and there is a residual component that can simply not be optically bleached (e.g. Voinchet et al., 2003; Tissoux et al., 2012). Since the level of this residual ESR intensity is sample dependent, it must be thus systematically evaluated for every sample analyzed in order to avoid $D_{E}$ overestimations. Laboratory experiments suggest that several tens of days would be required in the nature to reset the signal to its residual level (durations of bleaching may vary quite a lot depending on both the samples and experimental conditions, e.g. Rink et al., 2007; Toyoda et al., 2000; Tissoux et al., 2007; Voinchet et al., 2003), even though a field study by Voinchet et al. (2007) showed instead that a complete bleaching of the signal might nevertheless be obtained quite fast, i.e. within the first $1 \mathrm{~km}$ of transportation. Consequently, given these long durations, when using the $\mathrm{Al}$ center alone for dating purpose there is some uncertainty on whether complete bleaching has been achieved (i.e., whether the ESR signal has been reset to its residual component) prior to sediment deposition. If not, then calculated ESR-Al ages would overestimate the true age. This is why ESR age estimates derived from the Al center and based on the assumption of a complete bleaching should be considered in first instance as maximum possible ages (unless evidence of sediment reworking leading to partial resetting of the signal): this calculated age may be either consistent with the true age of the deposits, or older, but in any case not younger. To avoid misunderstandings, such consideration does not mean that ESR$\mathrm{Al}$ ages are systematically overestimated, as several dating 

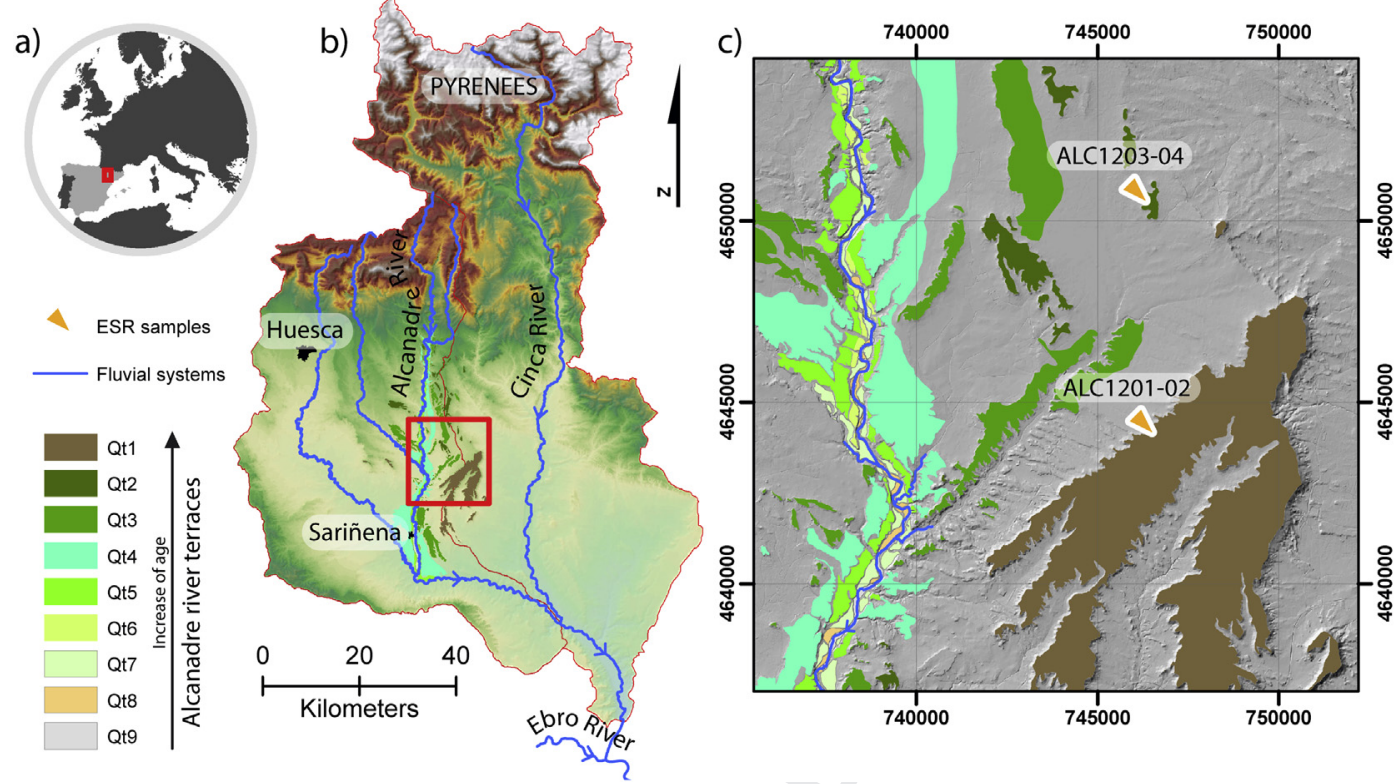

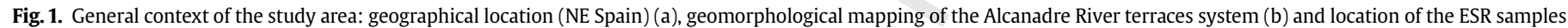
collected in Qt1 and Qt2 terraces (c).

studies have already previously shown ESR dating results being consistent with independent age control (e.g. Duval et al., 2015; Rink et al., 2007), thus indirectly confirming that the initial assumption of a complete resetting of the bleachable component of the ESR-Al signal was correct in these cases.

Perhaps the main challenge in ESR dating of optically bleached quartz grains based the $\mathrm{Al}$ center consists in minimizing this uncertainty, and several strategies may be employed for this purpose. One of them is to get a good independent age control, as previously mentioned (e.g. Duval et al., 2015; Rink et al., 2007). Another option would be to collect modern analog sediment samples from a similar environment to that of the sediment dated, in order to use it as a proxy of the bleaching conditions in the past. However, the reliability of this approach is limited by many factors (e.g. Jain et al., 2004), and the basic assumption that actual and past bleaching conditions were similar can hardly be verified, so that it might actually bring more uncertainty on the age result. But the best option is probably to take advantage of the presence of other lightsensitive ESR signals in quartz. In that regard, the Ti-centers, namely the $\mathrm{Ti}-\mathrm{Na}, \mathrm{Ti}-\mathrm{H}$ and $\mathrm{Ti}-\mathrm{Li}$ centers depending on the compensating cation, have a signal that may be zeroed by sunlight exposure. The intensity of the $\mathrm{Ti}-\mathrm{H}$ center can apparently be zeroed within a day, while it might take less than 20 days for the $\mathrm{Ti}-\mathrm{Li}$ center (e.g. Toyoda et al., 2000; Rink et al., 2007; Tissoux et al., 2007). Even though these durations are quite variable from one study to another and are clearly sample dependant, the bleaching kinetics of the Ti centers is nevertheless undoubtedly much faster than that of the $\mathrm{Al}$ center.

Assuming that all the centers from a given quartz sample should actually provide the same estimation of the dose effectively absorbed by this sample during its burial, any difference in the $\mathrm{D}_{\mathrm{E}}$ values derived from the $\mathrm{Al}$ and Ti centers would simply be due to incomplete bleaching of the former prior to sediment deposition. This is the basic principle of the MC approach proposed by Toyoda et al. (2000), but from a practical perspective its verification is actually limited by the difficulty to measure the Ti center in routine. The ESR intensity of this signal is usually quite low, significantly lower than that of the Al center. Achieving repeatable measurements is quite a challenge given the low signal to noise $(\mathrm{S} / \mathrm{N})$ ratios
(Duval and Guilarte, 2015) that require to keep the experimental conditions at low temperature stable for much longer times than with the Al center. For example, based on our experience, and with our analytical procedure, the ESR measurement of all the aliquots of a given sample may take around $1 \mathrm{~h}$ for the $\mathrm{Al}$ center and between 3 and $5 \mathrm{~h}$ for the Ti center. This is probably the main reason why the MC approach has been finally very little tested for dating purpose (e.g. Rink et al., 2007; Tissoux et al., 2007, 2008; Burdette et al., 2013), most of the studies being rather focused on a single center (e.g. Voinchet et al., 2010; Moreno et al., 2012; Liu et al., 2010, etc.). In addition, if there has been for many years an uncertainty about the stability of the signal associated to the Ti centers over a long time range, the consistent results obtained by Rink et al. (2007) suggest the Ti-Li center may actually be useful up to the Early Pleistocene time range. In contrast, the interest of the $\mathrm{Ti}-\mathrm{H}$ center is very likely limited to Middle to Late Pleistocene deposits, since it is known to saturate much earlier with the dose (Tissoux et al., 2007; Duval and Guilarte, 2015).

More recently, Rink et al. (2007) pushed a bit further the basic principle of this MC approach by proposing a new criterion as a quality control on the calculated ESR age results: "both the Al signal and Ti signal ages must agree to insure accurate burial ages" (p. 1618). The relevancy of this criterion will be discussed in the present paper in the light of the results obtained from the Alcanadre terraces.

\subsection{The Alcanadre River system: chronostratigraphic context}

The Alcanadre River is a tributary of the Cinca River which in turn flows into the Ebro River (Northeastern Spain) (Fig. 1). Its headwaters are located in the External Pyrenees and it flows with a meridian trend across the Ebro southern foreland basin. The Alcanadre River developed an extensive Quaternary staircase terrace system made of nine strath or cut-in-bedrock terraces (Calle et al., 2013). These are named as follows, from the highest to the lowest: Qt1 (between $+200 \mathrm{~m}$ above the active channel in the northern part and $+160 \mathrm{~m}$ at the South of the valley), Qt2 $(+190-100 \mathrm{~m})$, Qt3 (+130 - $55 \mathrm{~m})$, Qt4 (+65 - $30 \mathrm{~m})$, Qt5 (+55 - $20 \mathrm{~m})$, Qt6 $(+40-25 \mathrm{~m}), \mathrm{Qt7}(+35-10 \mathrm{~m}), \mathrm{Qt} 8(+15-3 \mathrm{~m}), \mathrm{Qt9}$ (floodplain) 


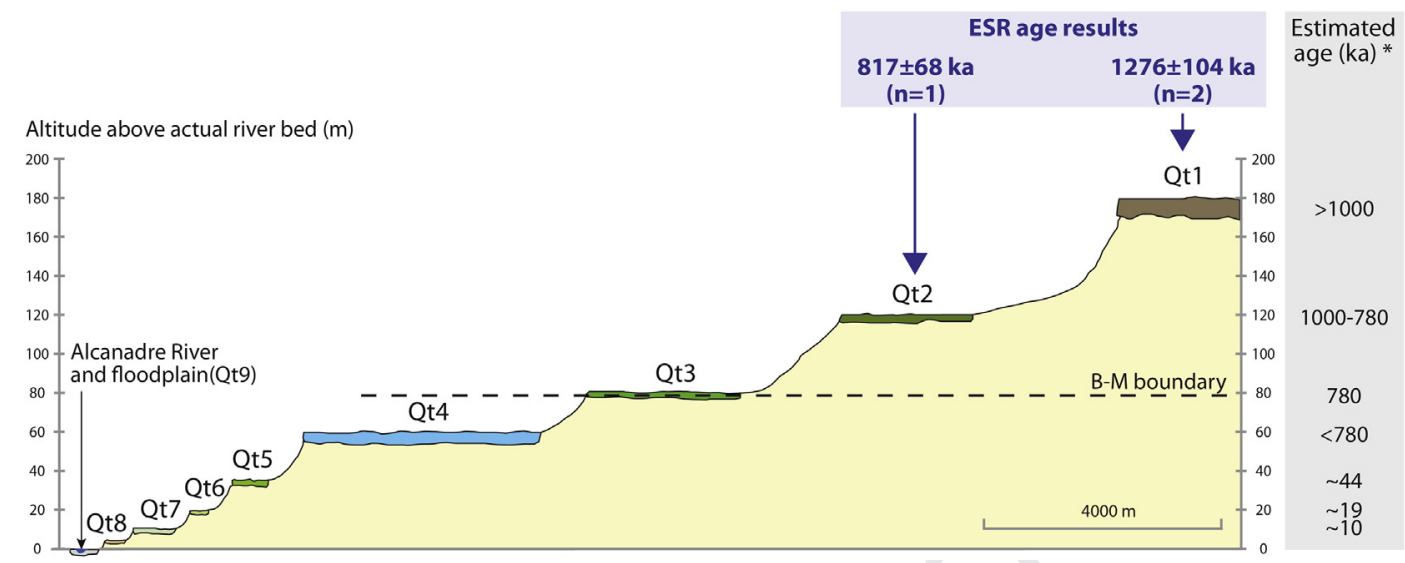

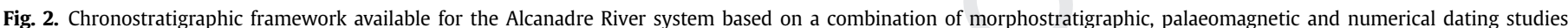

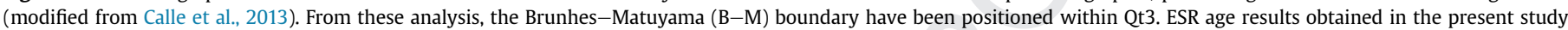

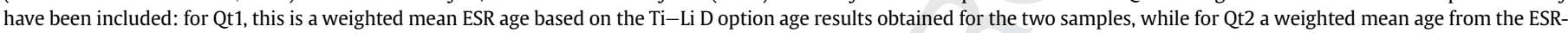

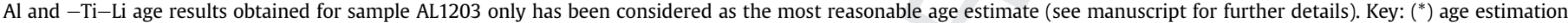
from Calle et al. (2013).

(Calle et al., 2013) (Fig. 2). Longitudinal profiles slightly diverge towards the headwaters located in South Pyrenees (Calle, 2012).

A combination of ongoing magnetostratigraphic and OSL dating studies has yielded a first insight of the chronostratigraphic framework of this terrace system. Preliminary numerical ages were obtained following a standard multiple quartz grains SAR procedure (180-250 $\mu \mathrm{m}$ size fraction). OSL dating performed on terraces Qt7 and Qt6 provided weighted mean ages of $9.9 \pm 0.4 \mathrm{ka}(\mathrm{n}=2)$ and $18.6 \pm 0.7 \mathrm{ka}(\mathrm{n}=3)$, respectively (Calle et al., 2013). Qt5 yielded a single OSL age estimate of $44 \pm 2 \mathrm{ka}$, while the samples were collected from Qt4 yielded only provided minimum ages given the saturation of the OSL signal. To complement these first results, sediment samples were collected for palaeomagnetic analysis from terrace Qt6 to Qt1. Current available data (Calle et al., 2013) require additional work to be validate and results should thus be taken as indicative. Normal polarities were identified for the terraces Qt6, Qt5 and Qt4, indicating thus that the deposits may be correlated to the Brunhes chron, which is consistent with the OSL dating results. In contrast, paleomagnetic data from the oldest terraces are somewhat more complex to interpret, since they showed reverse and normal polarities. According to its morphostratigraphic position, the age of Qt3 could be around the BrunhesMatuyama (B/M) boundary dated to $\sim 0.77 \mathrm{Ma}$ (Singer, 2014), while Qt2 did not yield any conclusive palaeomagnetic data. In a consistent morphostratigraphic framework, the reverse polarity identified within Qt1 should be attributed to the Matuyama chron, while the normal polarity interval could be tentatively correlated to a normal subchron (Jaramillo [ 1.01-1.08 Ma] or Cobb Mountain [ 1.19-1.22 Ma]; Singer, 2014). Although these preliminary data need to be refined in the future with additional sampling and analysis, they are nevertheless overall in fair agreement with the terrace sequence of the Cinca River valley (base level of the Alcanadre River) based on a combination of palaeomagnetic analysis, OSL dating and soil stratigraphy (Sancho et al., 2007; Lewis et al., 2009).

\section{Material and methods}

\subsection{Sediment samples}

Four sediment samples were collected in June 2012 (Fig. 3): two from the Qt1 terrace (ALC1201 and ALC1202) and other two from the Qt2 (ALC1203 and ALC1204). Altitude separation between both terraces exceeds $50 \mathrm{~m}$. Terrace treads are underlained by $11 \mathrm{~m}$ (Qt1) and $5 \mathrm{~m}$ (Qt2) of cobble-sized gravels in a sandy matrix with sparse sand lenses. Sand lenses were specifically selected for ESR sampling. Within Qt1, ALC1201 was coming from the upper part of the stratigraphic sequence, while ALC1202 was located about $10 \mathrm{~m}$ below, in the lower part of the section. In comparison, ALC1203 and ALC1204 were laterally distant by a few tens of meters from a given outcrop belonging to Qt2.

Sampling was performed by inserting opaque PVC tubes into the section. Additional sediment samples were collected at the same sampling spots for water content evaluation and further laboratory measurements. In situ measurements of the natural radioactivity were carried out with a $1.5 * 1.5$ inch $\mathrm{NaI}(\mathrm{Tl})$ probe coupled with an Canberra Inspector1000 multichannel analyzer (see details of the device in Arnold et al., 2012) at the exact location of the ESR samples.

\subsection{Analytical procedure}

\subsubsection{Sample preparation}

Sample preparation and ESR measurements were carried out at CENIEH (Burgos, Spain). Sediment samples were prepared in the laboratory under conditions of limited illumination. The $100-200 \mu \mathrm{m}$ size fraction was collected after wet sieving. $\mathrm{HCl}(36 \%)$ was used to dissolve carbonates and $\mathrm{H}_{2} \mathrm{O}_{2}$ (30\%) to eliminate organic matter. Heavy minerals and feldspars were removed with Sodium Polytungstate (SPT) solutions at $\mathrm{d}=2.72$ and $\mathrm{d}=2.62 \mathrm{~g} / \mathrm{ml}$, respectively. The resulting samples were treated with $\mathrm{HF}(40 \%)$ for 40 min to eliminate the remaining feldspars and to etch quartz grains. Then, $\mathrm{HCl}$ (18\%) was added in order to remove any soluble fluoride. Finally, magnetic minerals were eliminated using a strong neodymium magnet.

Quartz grains were dated by ESR using the Multiple Aliquots Additive (MAA) dose approach. Each natural sample was divided into 13 multiple grains aliquots. Eleven of these aliquots were irradiated using a ${ }^{137} \mathrm{Cs}$ Gammacell gamma source at the following doses: 197, 393, 590, 982, 1474, 2456, 4912, 7860, 11,789, 19,649, 29,473 and 49,121 Gy. The non-bleachable residual ESR signals of the Aluminum center were obtained after exposing one aliquot of each natural sample in a SOL2 (Dr Hönle) solar light simulator for about $1460 \mathrm{~h}$.

\subsubsection{ESR measurements}

ESR measurements were carried out with an EMXmicro 6/ 1Bruker X-band ESR spectrometer coupled to a standard 

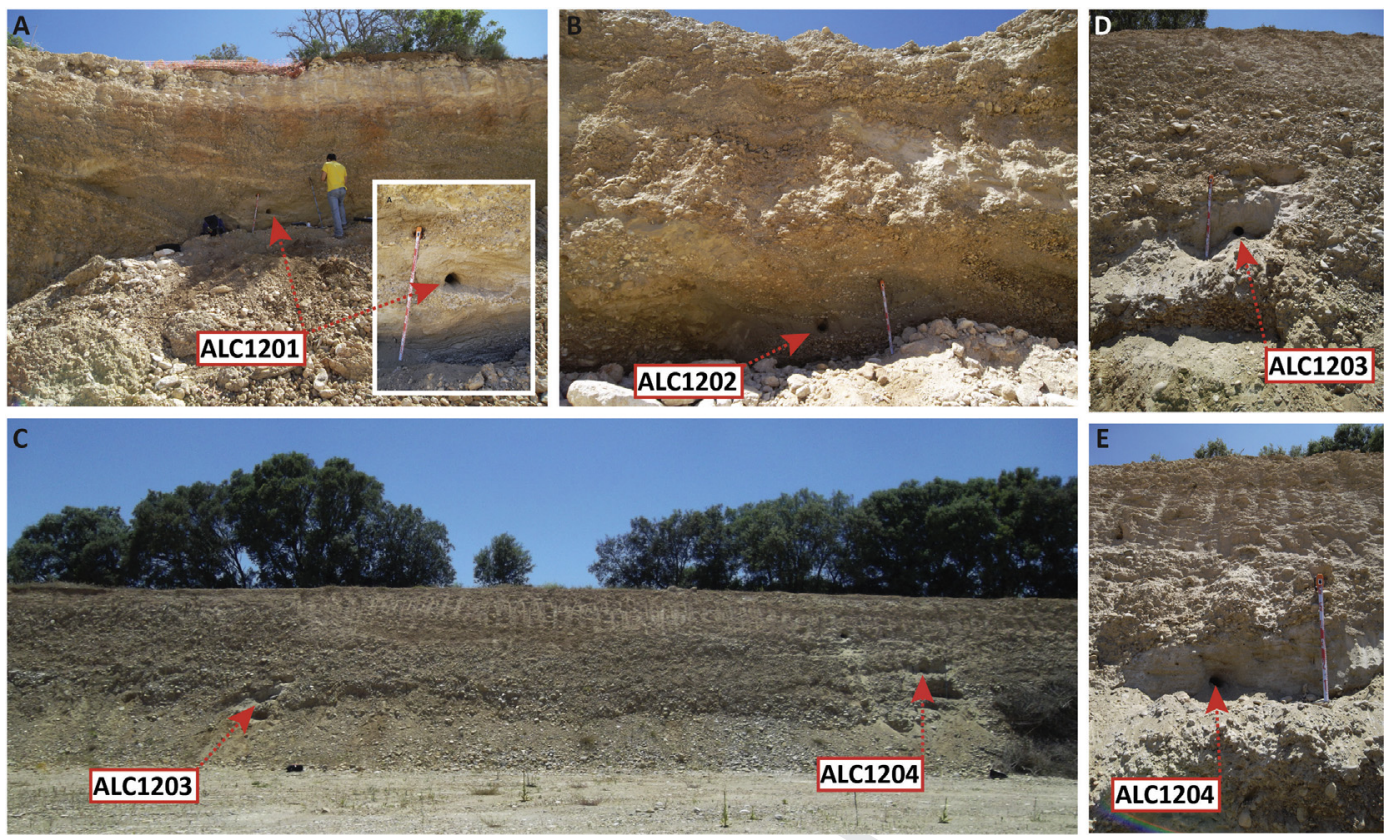

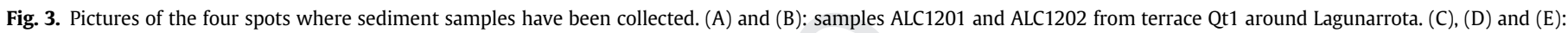
samples ALC1203 and ALC1204 from terrace Qt2 near Berbegal.

rectangular ER 4102ST cavity. To ensure constant experimental conditions over time, the temperature of the water circulating in the magnet is controlled and stabilized at $18{ }^{\circ} \mathrm{C}$ by a water-cooled Thermo Scientific NESLAB ThermoFlex 3500 chiller, and the temperature of the room is kept constant at $20^{\circ} \mathrm{C}$ by an air conditioning unit. ESR measurements were performed at low temperature ( $90 \mathrm{~K})$ using a ER4141VT Digital Temperature control system based on liquid nitrogen cooling. Further details about the setup and about its stability over time can be found in Duval and Guilarte Moreno (2012).

Following the MC method suggested by Toyoda et al. (2000), both ESR signals of the Aluminum ( $\mathrm{Al}$ ) and Titanium (Ti) centers were studied. For the ESR signal associated to the Al center, the following acquisition parameters were used: $10 \mathrm{~mW}$ microwave power, 1024 points resolution, $20 \mathrm{mT}$ sweep width, $100 \mathrm{kHz}$ modulation frequency, $0.1 \mathrm{mT}$ modulation amplitude, $40 \mathrm{~ms}$ conversion time, $20 \mathrm{~ms}$ time constant and 1 scan. In contrast, the ESR signal associated to the Ti centers was measured as follows: $5 \mathrm{~mW}$ microwave power, 1024 points resolution, $20 \mathrm{mT}$ sweep width, $100 \mathrm{kHz}$ modulation frequency, $0.1 \mathrm{mT}$ modulation amplitude, $60 \mathrm{~ms}$ conversion time, $40 \mathrm{~ms}$ time constant and between 2 and 4 scans to ensure a reasonable $\mathrm{S} / \mathrm{N}$ ratio. Each of the thirteen aliquots (one natural, one optically bleached and eleven gamma irradiated aliquots) of a given sample were measured 3 times after a $\sim 120^{\circ}$ rotation in the cavity in order to consider angular dependence of the signal due to sample heterogeneity. Then, measurements were repeated three times over distinct days in order to check the reproducibility of the $D_{E}$ values. This procedure was carried out for both the $\mathrm{Al}$ and Ti signals. Examples of ESR spectra are shown in Fig. 4.

\subsection{3. $D_{E}$ determination}

The ESR intensity of the Al signal was extracted from peak-topeak amplitude measurements between the top of the first peak $(\mathrm{g}=2.0185)$ and the bottom of the 16 th peak $(\mathrm{g}=1.9928)$ (Toyoda and Falguères, 2003). Following the conclusions from Duval and Guilarte (2015), the ESR intensity of the Ti centers was measured in three different ways (Fig. 4):
- Peak-to-peak amplitude measurement between $\mathrm{g}=1.979$ and the bottom of the peak at $\mathrm{g}=1.913$ (option A).

- Peak-to-baseline amplitude measurement around $\mathrm{g}=1.913-1.915$ (option D).

- Peak-to-baseline amplitude measurement around $\mathrm{g}=1.915$ ( Ti-H center).

Actually, options A and D are most likely made by a mixture of $\mathrm{Ti}-\mathrm{Li}$ and $\mathrm{Ti}-\mathrm{H}$ centers since they have both a line around $\mathrm{g}=1.913$, but results from Duval and Guilarte (2015) suggested that the contribution from the $\mathrm{Ti}-\mathrm{H}$ line was in most cases not significant. In contrast, the left peak at $\mathrm{g}=1.915$ is only made by the contribution of the $\mathrm{Ti}-\mathrm{H}$ center.

For each aliquot, final ESR intensities of $\mathrm{Al}$ and Ti centers corresponded to the mean values derived from the repeated measurements, previously corrected by the corresponding receiver gain value, number of scans, aliquot mass and a temperature correction factor (Duval and Guilarte Moreno, 2012). The fitting procedures were carried out with the Microcal OriginPro 9.1. software using a Levenberg-Marquardt algorithm by chi-square minimization. For the Al center, an exponential + linear function (EXP + LIN) was fitted through the experimental points, and data were weighted by the inverse of the squared ESR intensity $\left(1 / \mathrm{I}^{2}\right)$. $D_{E}$ values were obtained by extrapolating the EXP + LIN function to the residual ESR intensity (so-called total bleach method, Forman et al., 2000). For the Ti-centers, two fitting functions were tested for $\mathrm{D}_{\mathrm{E}}$ calculation as described in Duval and Guilarte (2015): the single saturating exponential function (SSE) and the so-called Ti-2 function, which was initially proposed by Woda et Wagner (2007). Equations of the fitting functions are provided in supplementary information. With the SSE, data were weighted by the inverse of the squared ESR intensity $\left(1 / \mathrm{I}^{2}\right)$, whereas equal weights were used with the function Ti-2. The goodness-of-fit was assessed through the adjusted $r$-square $\left(r^{2}\right)$ value, which accounts for the degrees of freedom of the system, contrary to the classical coefficient of determination $\mathrm{r}^{2}$ (see the Origin 8 User Guide for further details). Two examples of dose response curves (DRCs) are given in Fig. 5. 

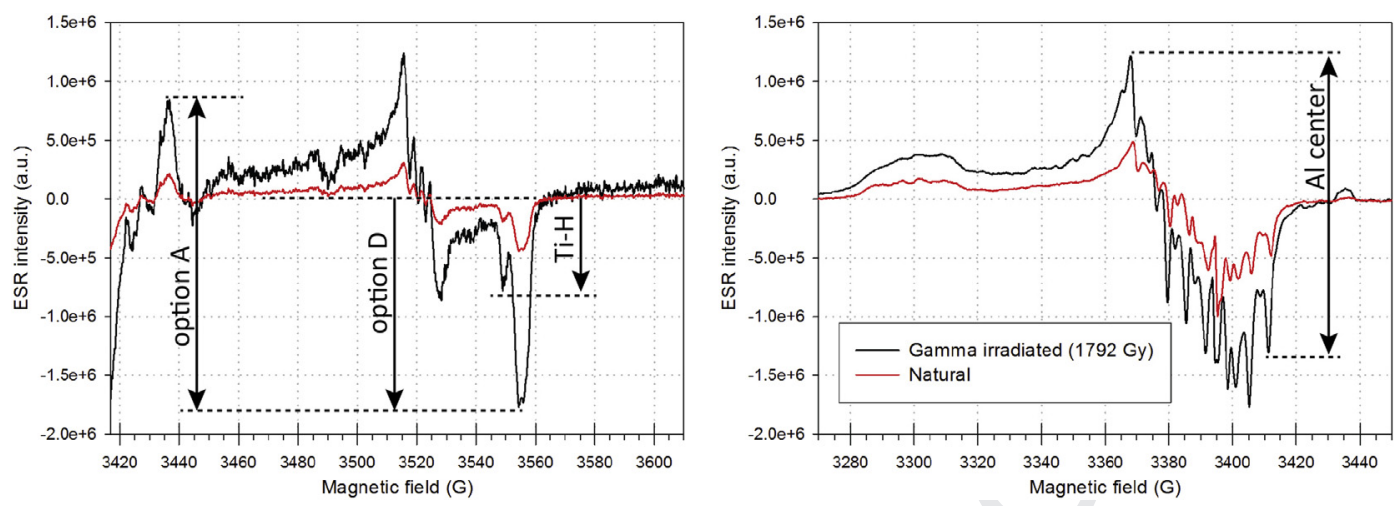

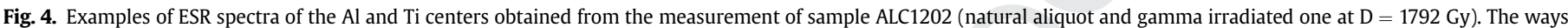
ESR intensities are extracted are also indicated. Left: ESR signal of the Ti-centers; Right: ESR signal of the Al center.

\subsubsection{Dose rate evaluation and ESR age calculation}

The total dose rate value was derived from a combination of in situ and laboratory measurements. External gamma dose rate were derived from in situ measurements by using the "threshold technique" (Duval and Arnold, 2013). For each dated samples, the corresponding radioelement $(\mathrm{U}, \mathrm{Th}, \mathrm{K})$ concentrations in the sediment were determined by ICP-/MS analysis of about $5 \mathrm{~g}$ of dry raw sediment. In addition, $\sim 150 \mathrm{~g}$ of this same raw sediment, previously dried and powdered, were analysed by High Resolution Gamma pectrometry (HRGS) using a Canberra Extended Range (XtRa) HpGe detector in order to identify possible disequilibrium in the U-238 decay chain. Concentration values were used to derive external alpha and beta dose rate components using the dose rate conversion factors from Guérin et al. (2011). Dose rate values were calculated assuming a mean grain size of $150 \mu \mathrm{m}$, and an assumed thickness removed by HF etching of $20 \mu \mathrm{m}$. Values were corrected with beta and alpha attenuation values for spherical grains (Brennan et al., 1991; Brennan, 2003) and water attenuation formulae from Grün (1994). Actual and saturated water contents were evaluated in the laboratory by drying the sediment at $50^{\circ} \mathrm{C}$ in an oven during three weeks. Internal dose rate was assumed to be $50 \pm 30 \mathrm{uGy} / \mathrm{a}$, based on the work from Vandenberghe et al. (2008) and assuming an alpha efficiency $\mathrm{k}$ of $0.15 \pm 0.10$ (Yokoyama et al., 1985). The cosmic dose rate was calculated using formulae from Prescott and Hutton (1994), with depth, altitude and latitude corrections (Prescott and Hutton, 1988).

ESR age calculation were performed using a non commercial SCILAB based software, with error calculations based on Monte Carlo simulations, considering the following sources of uncertainties: concentrations, depth, water content, in situ gamma dose rate, beta dose rate attenuations, $D_{E}$ values. ESR ages are given at $1 \sigma$.

\section{Results and discussion}

\subsection{ESR data}

All the DRCs derived from the evaluation of the Al, Ti- $\mathrm{Li} \mathrm{A}$ option, Ti-Li D option, and Ti-H centers for the four quartz samples are shown in supplementary information (Fig. S1 to S4). All experimental ESR intensities are given in Table S2 to S7.

\subsubsection{Al center}

Regarding the Al center, repeated ESR measurements carried out for each sample showed a very good reproducibility of the $D_{E}$ values, with a variation between 3 and 5\% for three samples and around $7 \%$ for sample ALC1203. In other words, all $\mathrm{D}_{\mathrm{E}}$ values derived from measurements performed on three different days were within error at 1 sigma for a given sample. Consequently, for a given sample, a final $D_{E}$ value was calculated by considering for each aliquot the average ESR intensities from the three repeated measurements.

The relative bleached component values calculated for the 4 samples are all very close ( 59-60\%), indicating similar bleaching conditions. A slight difference may be observed between samples from Qt1 and Qt2, but it does not seem to be significant (Table 1). From a methodological point of view, following some of the criteria defined for fossil tooth enamel (Duval et al., 2013), fitting results

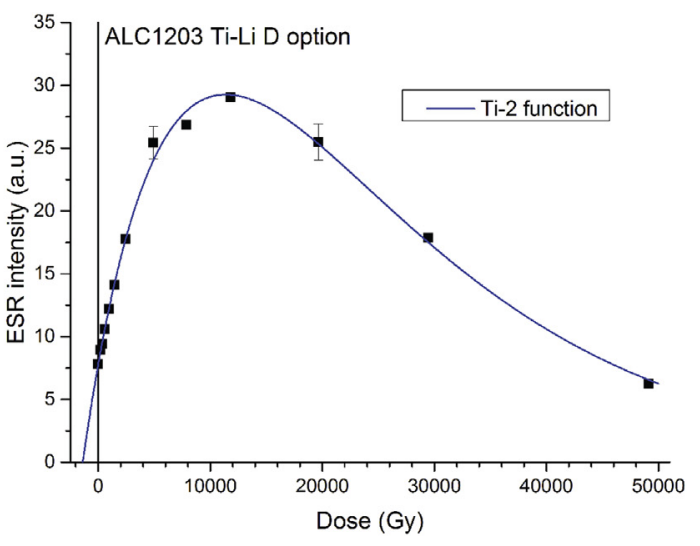

Fig. 5. Examples of two DRCs obtained in the present work. Left: Sample ALC1201, Al center. Right: sample ALC1203, Ti-Li D option. 
may be considered as reliable: Adjusted $r^{2}$ values are systematically $>0.99$, indicating an excellent goodness-of-fit, and relative errors on each fitted parameter are $<25 \%$. Relative age errors $(1 \sigma)$ are ranging between 8\% (ALC1202) and 13\% (ALC1201) and are on average around $10.4 \%$. $D_{E}$ values obtained for samples from $Q t 1$ are higher and somewhat more scattered than those obtained for Qt2, but all $D_{E}$ values are nevertheless consistent within error for a given terrace.

\subsubsection{Ti-Li center}

For the evaluation of the Ti-Li center, we followed the quality control procedures recommended by Duval and Guilarte (2015): ESR intensities were measured following options A and D (Fig. 4) and $D_{E}$ values were calculated using both the SSE (with $\mathrm{D}_{\max }=12 \mathrm{kGy}$, i.e. the dose corresponding to the maximum ESR intensity) and Ti-2 functions (on full dose range). Results were overall consistent at $1 \sigma$ (see summary Table S8), whatever the function or option considered, indicating thus the reliability of the dataset. In addition, repeated ESR measurements carried out for each sample on different days showed a very good reproducibility of the $D_{E}$ results: a relative variation between 1 and $9 \%$ was observed, depending on the samples, and all $D_{E}$ values derived from repeated measurements were within $1 \sigma$ error for a given sample. Consequently, in agreement with the recommendations by Duval and Guilarte (2015), a final $D_{E}$ value was calculated for a given sample by using a Ti-2 function (with equal weights, EW) and considering for each aliquot the average ESR intensities (taken from option D) from the three repeated measurements.

Fitting results fulfillfulfill the criteria defined in Duval and Guilarte (2015) to ensure a reliable fitting. Adjusted $r^{2}$ values are systematically $>0.99$, showing a high goodness-of-fit. For three of the four samples, $D_{\mathrm{E}}$ values are somewhat lower than those derived from the Al center, the exception being ALC1204. It seems nevertheless that each terrace shows a different pattern: for samples from Qt1, the deviation between $\mathrm{D}_{\mathrm{E}}(\mathrm{Al})$ and $\mathrm{D}_{\mathrm{E}}(\mathrm{Ti})$ is quite important, between $14 \%$ and $20 \%$, whereas for the other samples from Qt2 deposits, the two data sets are much closer, with a relative difference of $6 \%$ max. This might indicate that the ESR signal of the $\mathrm{Al}$ center has been fully, or almost, bleached for the samples from Qt2, while it does not seem the case for the samples from Qt1. These data suggest different transportation and bleaching conditions between the deposits of each terrace.

Finally, it should be mentioned that Ti-Li E option has also been tentatively measured as defined by Duval and Guilarte (2015), since it is virtually the only way to measure the contribution of the $\mathrm{Ti}-\mathrm{Li}$ center alone. However, the fitting carried out with the Ti-2 function on the four samples did not provide reliable results, as the adj. $\mathrm{r}^{2}$ values were between 0.80 and 0.85 (indicating thus a poor goodness-of-fit), and the relative $\mathrm{D}_{\mathrm{E}}$ errors were ranging from $55 \%$ to $65 \%$. Consequently, no conclusive results could be obtained with option E for these four samples.

\subsubsection{Ti-H center}

For information, the fitting results derived from the measurement of the Ti-H center (option C in Duval and Guilarte, 2015) are also provided (Table 1). DRCs are shown in supplementary information. This center potentially offers many interests for dating purpose, and especially to detect small dose values given its higher radiation sensitivity in comparison with the other Al and Ticenters (e.g. Duval and Guilarte, 2015). In addition, it also shows a faster bleaching kinetics (e.g. Tissoux et al., 2007), minimizing thus the uncertainty associated to potential incomplete bleaching prior to sediment deposition. However, the low ESR intensity of the signal makes it in general quite difficult to measure, resulting in scattered DRC and unsatisfactory goodness-of-fit (e.g. Duval and Guilarte, 2015). In addition, the ability of this center to accurately register dose values higher than a few hundreds of Gy has been questioned (e.g. Asagoe and Toyoda, submitted), leaving quite a large uncertainty about its interest for dating Early Pleistocene samples.

Repeated measurements performed on the four samples show good reproducibility in the $\mathrm{D}_{\mathrm{E}}$ values, which are varying within a narrow range (between 0.4 and 6.7\%). Consequently, final $\mathrm{D}_{\mathrm{E}}$ values were calculated by considering the average ESR intensity over the three repeated measurement for each aliquot of a given sample.

Final $D_{E}$ values derived from the Ti-2 function are ranging from $886 \pm 273$ and $1395 \pm 379$ Gy (Table 1 ). However, these data should be considered with much caution, since they actually do not fulfil the standards defined by Duval and Guilarte (2015) to ensure a reliable fitting. The very low $\mathrm{r}^{2}$ values $(<0.95)$ indicate a very poor goodness-of-fit. This may be clearly observed on the DRCs shown in supplementary information. If $D_{\mathrm{E}}$ values consistent at 1 sigma with those derived from the Ti-Li signal, this is only the result of very large $D_{E}$ errors. Actually, $D_{E}$ values are systematically lower than those from the Ti-Li signal, which is most likely because the $\mathrm{Ti}-\mathrm{H}$ signal saturates much earlier with the dose (around $2000 \mathrm{~Gy}$ for the four samples). This is in agreement with previous observations (e.g. Tissoux et al., 2007; Duval and Guilarte, 2015). The use of an SSE until apparent saturation $\left(D_{\max }=5 \mathrm{kGy}\right)$ instead of the Ti-2 function may seem more appropriate in this case since adj. $\mathrm{r}^{2}$ result in similar or higher values, but they nevertheless remain overall below the standards to ensure reliable fitting (between 0.9812 and $0.9113)$. With this function, calculated $D_{E}$ values are even smaller in comparison with those derived from the Ti-2 function (see summary Table S8). If these data are definitely not reliable enough to draw any definitive conclusion, they nevertheless seem to confirm the limited interest of this signal for samples with doses $>1 \mathrm{kGy}$.

\subsection{Dose rate evaluation}

Radioelement contents were determined by ICP-OES/MS and HRGS and Table 2 shows that these two techniques provide very consistent results. Except for two values, the relative deviation for a given element is not exceeding 3\%. Actually, all but two activity values are in agreement at $1 \sigma$, and all of them are in agreement at $2 \sigma$. HRGS values indicate that no significant disequilibrium is observed in the U-238 series of the four sediment samples, activity values for Rn-222 and U-238 being all consistent within error.

Table 1

ESR data and fitting results obtained for $\mathrm{Al}$ and Ti centers.

\begin{tabular}{|c|c|c|c|c|c|c|c|}
\hline \multirow[t]{2}{*}{ Sample } & \multicolumn{3}{|l|}{$\mathrm{Al}$} & \multicolumn{2}{|c|}{ Ti-Li D option } & \multicolumn{2}{|l|}{$\mathrm{Ti}-\mathrm{H}$} \\
\hline & Bleach. coef. (\%) & Adj. $r^{2}$ & $D_{E}(G y)$ & $\overline{\text { Adj. } \mathrm{r}^{2}}$ & $\overline{T i-2} D_{E}(G y)$ & $\overline{\text { Adj. } \mathrm{r}^{2}}$ & $\overline{T i-2} D_{E}(G y)$ \\
\hline ALC1201 (Qt1) & $60.6 \pm 1.3$ & 0.99185 & $1827 \pm 237$ & 0.99460 & $1566 \pm 115$ & 0.94228 & $1395 \pm 379$ \\
\hline ALC1202 (Qt1) & $60.1 \pm 1.4$ & 0.99652 & $1535 \pm 128$ & 0.99238 & $1221 \pm 115$ & 0.92931 & $886 \pm 273$ \\
\hline ALC1203 (Qt2) & $59.3 \pm 1.2$ & 0.99484 & $1443 \pm 157$ & 0.99377 & $1381 \pm 113$ & 0.85365 & $931 \pm 436$ \\
\hline ALC1204 (Qt2) & $59.2 \pm 1.3$ & 0.99577 & $1389 \pm 130$ & 0.99359 & $1478 \pm 119$ & 0.92009 & $1092 \pm 352$ \\
\hline
\end{tabular}


Table 2

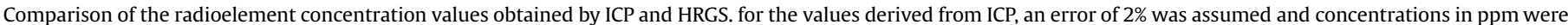
converted into activity values for facilitating the comparison.

\begin{tabular}{|c|c|c|c|c|c|c|c|}
\hline \multirow[t]{2}{*}{ Sample } & \multicolumn{3}{|c|}{ ICP measurements } & \multicolumn{4}{|c|}{ High resolution Gamma spectrometry } \\
\hline & $\mathrm{U}-238(\mathrm{~Bq} / \mathrm{kg})$ & Th-232 (Bq/kg) & $\mathrm{K}-40(\mathrm{~Bq} / \mathrm{kg})$ & $\mathrm{U}-238(\mathrm{~Bq} / \mathrm{kg})$ & $\mathrm{Rn}-222(\mathrm{~Bq} / \mathrm{kg})$ & Th-232 (Bq/kg) & $\mathrm{K}-40(\mathrm{~Bq} / \mathrm{kg})$ \\
\hline ALC1201 (Qt1) & $11.563 \pm 0.231$ & $15.228 \pm 0.305$ & $0.912 \pm 0.018$ & $13.177+1.262$ & $12.609+0.881$ & $14.914 \pm 0.925$ & $0.882 \pm 0.029$ \\
\hline ALC1202 (Qt1) & $12.558 \pm 0.247$ & $12.541 \pm 0.251$ & $0.796 \pm 0.016$ & $12.876+1.230$ & $13.020+0.846$ & $12.191 \pm 0.750$ & $0.722 \pm 0.024$ \\
\hline ALC1203 (Qt2) & $14.671 \pm 0.289$ & $20.603 \pm 0.412$ & $1.329 \pm 0.027$ & $14.794+1.406$ & $13.622+0.885$ & $20.865 \pm 1.249$ & $1.296 \pm 0.043$ \\
\hline ALC1204 (Qt2) & $10.765 \pm 0.215$ & $11.849 \pm 0.237$ & $0.706 \pm 0.014$ & $10.967+1.063$ & $10.419+0.682$ & $11.815 \pm 0.742$ & $0.699 \pm 0.023$ \\
\hline
\end{tabular}

Table 3 shows a comparison of gamma dose rate values derived from in situ and laboratory (ICP and HRGS) measurements. As expected, the gamma dose rates derived from laboratory measurements and assuming either equilibrium or disequilibrium in the U238 series are all consistent at 1 sigma. However, when comparing these values with those derived from in situ measurements, significant deviations may be observed: the values measured in situ are systematically lower by between 3\% (ALC1204) and 39\% (ALC1202). Actually, such a difference is not really a surprise, given the heterogeneity of the sedimentary context: as one may observe on Fig. 3, samples were systematically collected within lenses of fine sands surrounded by coarser deposits. This actually demonstrates the importance to carry out in situ measurements when collecting samples for ESR dating purpose in particular in a nonhomogeneous sedimentary context, as frequently observed in fluvial environment. It is easier, faster and undoubtedly more accurate than collecting several sediment samples in the surroundings of the sample dated by ESR for reconstructing the radioactive environment from laboratory measurements, which are based on only a limited amount of material (between a few grams and $<200 \mathrm{~g}$ of sediment). Actually, laboratory analysis should be preferentially used to derive alpha and beta dose rates, while the values measured in situ, at the exact location of the sample, should be intended for the evaluation of the gamma dose rate (see also Duval, in press).

\subsection{ESR age estimates}

ESR age estimates were calculated using the $\mathrm{D}_{\mathrm{E}}$ values derived from both the $\mathrm{Al}$ and Ti-Li D option centers, alpha and beta dose rates based on ICP-OES/MS measurements and in situ gamma dose rates values. Results are shown in Table 4 . The actual water content was found to be below $5 \%$ for all the samples, but the final water content used for the dose rate evaluation was assumed to be around $60 \%$ of the saturated water content measured in the laboratory. The resulting values are ranging from 16 to $20 \%$. A quite large error of $5 \%$
$(1 \sigma)$ was assumed in order to encompass any possible long and short term variations of the water content over time.

ESR age estimates based on the $\mathrm{Al}$ center are consistent at 1 sigma for the two samples from Qt1 terrace, whereas they are more scattered for Qt2. The same pattern is observed for the Ti-based age results. All ages are nevertheless consistent in indicating an Early Pleistocene chronology for both terraces. Age errors $(1 \sigma)$ are between $11.6 \%$ and $15.2 \%$ and between $10.8 \%$ and $12.4 \%$ for the $\mathrm{Al}$ and $\mathrm{Ti}-\mathrm{Li} \mathrm{D}$ option centers, respectively. For Qt1, ESR-Al ages are around 1.50-1.60 Ma, while ESR-Ti ages are in agreement at $1 \sigma$, but nevertheless younger, around $1.25-1.30 \mathrm{Ma}$. Weighted mean age values of $1566 \pm 145 \mathrm{ka}$ and $1276 \pm 104 \mathrm{ka}$ may be calculated for Qt1 terrace formation based on $\mathrm{Al}$ and Ti-centers from the two samples, respectively. Following the principle of the MC approach, such a difference in the ages may be interpreted as an evidence of an incomplete bleaching of the $\mathrm{Al}$ center prior to sediment deposition, given its slower bleaching kinetics in comparison with the Ti center (Toyoda et al., 2000). ESR-Al age estimates should be thus considered as maximum possible ages, whereas the ESR-Ti age results are most likely a better estimation of the true age of the deposits (Fig. 2). In that regard, the weighted mean age of $1276 \pm 104 \mathrm{ka}$ based on $\mathrm{Ti}-\mathrm{Li}$ centers is in good agreement with the preliminary existing chronostratigraphic framework suggesting an Early Pleistocene chronology for Qt1. The normal polarity interval identified by Calle et al. (2013) lead the authors to suggest a correlation with a normal subchron such as Jaramillo ( 1.01-1.08 Ma) or Cobb Mountain ( 1.19-1.22 Ma) (Singer, 2014), which is consistent with the ESR chronology available for this terrace.

Regarding Qt2 samples, age estimates are very scattered, with $842 \pm 109$ and $1317 \pm 159 \mathrm{ka}$ (Al center) for samples ALC1203 and ALC1204, respectively. The ESR age estimates based on the Al center differ by a factor $>50 \%$, but are nevertheless consistent at 2 sigma, while there is a factor of $75 \%$ of difference for the $\mathrm{Ti}-\mathrm{Li}$ age estimates. However, in contrast with Qt1 terrace, the chronologies provided by each center are actually highly consistent for a given sample (Table 4), suggesting thus a complete, or almost, bleaching

Table 3

Comparison of gamma dose rates derived from in situ and laboratory measurements.

Measured water content (\%)

\begin{tabular}{lll} 
& \\
\hline ALC1201 (Qt1) & 1.1 & 4.1 \\
ALC1202 (Qt1) & 41 & 313 \\
ALC1203 (Qt2) & 4.4 & 5.1 \\
ALC1204 (Qt2) & 3.1 \\
\hline a Gamma dose rate calculated using the full series dose \\
by the measured water content for a given sample.
\end{tabular}

Gamma dose rate $(\mu \mathrm{Gy} / \mathrm{a})$

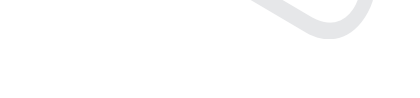

ALC1202 (Qt1) 4.1

Gamma dose rate $(\mu \mathrm{Gy} / \mathrm{a})$

b Calculation performed assuming that a constant disequilibrium has prevailed over time within the U-238 series (pre-Rn dose rate conversion factors from Guérin et al., 2011) and attenuated by the measured water content for a given sample.
ALC1201 (Qt1)

ALC1203 (Qt2) 4.4

ALC1204 (Qt2) $\quad 3.1$

\begin{tabular}{lll} 
& \\
\hline ALC1201 (Qt1) & 1.1 & 4.1 \\
ALC1202 (Qt1) & 4.4 & 3.1 \\
ALC1203 (Qt2) & ALC1204 (Qt2) & 3 \\
\hline a Gamma dose rate calculated using the full series dose \\
by the measured water content for a given sample.
\end{tabular}

the measured water content for a given sample.
2

Threshold

Laboratory

$\overline{\text { ICP full series }}{ }^{\mathrm{a}}$

+27
+19

$500 \pm 17$

$434 \pm 15$

$666 \pm 23$

$394 \pm 14$

\begin{tabular}{|c|c|}
\hline 1 & 2 \\
\hline In situ & Laboratory \\
\hline Threshold & ICP full series ${ }^{a}$ \\
\hline $451 \pm 27$ & $500 \pm 17$ \\
\hline $313+19$ & $434 \pm 15$ \\
\hline $574+34$ & $666 \pm 23$ \\
\hline $382 \pm 23$ & $394 \pm 14$ \\
\hline
\end{tabular}
RCS Pre- $\operatorname{Rn}^{\mathrm{b}}$ $499 \pm 67$ $416 \pm 54$ $53 \pm 83$ $90 \pm 51$

\begin{tabular}{l}
$\frac{4}{\text { Laboratory }}$ \\
\hline HRGS full series \\
$503 \pm 60$ \\
$415 \pm 49$ \\
$662 \pm 78$ \\
$394 \pm 47$
\end{tabular}

\begin{tabular}{llll}
\hline $2 / 1$ & $4 / 1$ & $4 / 2$ & $4 / 3$
\end{tabular}

1.39

1.16

1.03

$\begin{array}{lll}1.12 & 1.01 & 1.01 \\ 1.33 & 0.96 & 1.00 \\ 1.15 & 0.99 & 1.01 \\ 1.03 & 1.00 & 1.01\end{array}$


Table 4

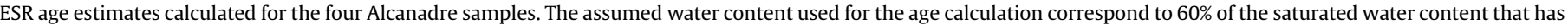
been determined the laboratory, with an associated uncertainty of $5 \%$.

\begin{tabular}{|c|c|c|c|c|}
\hline Sample & ALC1201 & ALC1202 & ALC1203 & ALC1204 \\
\hline Terrace & Qt1 & Qt1 & Qt2 & Qt2 \\
\hline $\begin{array}{l}\text { Depth (m) } \\
\text { Assumed water content (\%) }\end{array}$ & $\begin{array}{l}4 \pm 2 \\
20 \pm 5\end{array}$ & $\begin{array}{l}14 \pm 2 \\
18 \pm 5\end{array}$ & $\begin{array}{l}3 \pm 2 \\
16 \pm 5\end{array}$ & $\begin{array}{l}2.5 \pm 1 \\
20 \pm 5\end{array}$ \\
\hline $\begin{array}{l}\text { Internal dose rate }(\mu G y / a) \\
\text { Alpha dose rate }(\mu G y / a) \\
\text { Beta dose rate }(\mu G y / a) \\
\text { Gamma dose rate }(\mu G y / a) \\
\text { Cosmic dose rate }(\mu G y / a) \\
\text { Total dose rate }(\mu G y / a)\end{array}$ & $\begin{array}{l}50 \pm 30 \\
18 \pm 15 \\
672 \pm 54 \\
356 \pm 33 \\
126 \pm 44 \\
1222 \pm 97\end{array}$ & $\begin{array}{l}50 \pm 30 \\
17 \pm 14 \\
601 \pm 53 \\
256 \pm 24 \\
37 \pm 8 \\
961+79\end{array}$ & $\begin{array}{l}50 \pm 30 \\
26 \pm 22 \\
1012 \pm 79 \\
495 \pm 44 \\
141 \pm 25 \\
1724 \pm 124\end{array}$ & $\begin{array}{l}50 \pm 30 \\
15 \pm 13 \\
534 \pm 42 \\
309 \pm 28 \\
152 \pm 28 \\
1060 \pm 79\end{array}$ \\
\hline $\begin{array}{l}D_{E}(G y) \text { Al } \\
D_{E}(G y) \text { Ti-Li D option }\end{array}$ & $\begin{array}{l}1827 \pm 237 \\
1566+115 \\
\end{array}$ & $\begin{array}{l}1535 \pm 128 \\
1221+115 \\
\end{array}$ & $\begin{array}{l}1443 \pm 157 \\
1381+113 \\
\end{array}$ & $\begin{array}{l}1389 \pm 130 \\
1478+119 \\
\end{array}$ \\
\hline $\begin{array}{l}\text { Age (ka) Al } \\
\text { Age (ka) Ti-Li D option }\end{array}$ & $\begin{array}{l}1504 \pm 229 \\
1282 \pm 139\end{array}$ & $\begin{array}{l}1606+187 \\
1269 \pm 157\end{array}$ & $\begin{array}{l}842+109 \\
801 \pm 87\end{array}$ & $\begin{array}{l}1317 \pm 159 \\
1394 \pm 152\end{array}$ \\
\hline
\end{tabular}

of the Al-ESR signal prior to deposition. This large difference in age (whatever the center considered) raises some interrogations about the true age of Qt2, since no meaningful mean value can be extracted from the two samples. Given these results, two main hypotheses may reasonably be envisaged: (i) either one of the two samples strongly underestimates or overestimates the true age of the deposits, (ii) or both ages accurately reflect the age of the deposits.

Actually, since the $D_{E}$ values are very similar, the difference between the two samples is most likely coming from the evaluation of the total dose rate: the value calculated for sample ALC1204 is significantly lower $(-40 \%)$ than that obtained for ALC1203. It is worth mentioning that sediment samples for laboratory analyses were systematically taken from the same exact spot where ESR samples were collected. Consequently, the possibility of an inaccurate external alpha and beta dose rate evaluation due to lateral variations of dosimetry in the sedimentary context may reasonably be excluded here. In addition, the overall excellent agreement between the ICP and HRGS results based on two subsamples of a few $g$ and $\sim 110 \mathrm{~g}$, respectively, show the homogeneity of the sediment at the ESR sampling points. Although concentrations of Th-232 and K40 measured for ALC1204 are actually almost half of the values of ALC1203 (Table 2), we do not observe any significant disequilibrium in the U-238 that could suggest a recent change in the geochemical conditions and significantly impact the dose rate in one direction or another. Another possibility would be that the estimation of the water content used in the age calculation might be inaccurate for one of the two samples. To test the impact of the water content on the calculated ages, simulations performed using a water content of $15 \pm 5$ and $10 \pm 5 \%$ for sample ALC1204 indicate that the ESR ages would be younger by about $6 \%$ and $11 \%$, respectively, i.e. still within error. Consequently, from a methodological perspective, we do not have any objective reason to discard the age obtained for one sample or the other.

However, it is also possible that both samples accurately reflect the true age of the deposits. Nevertheless, in the light of the ESR dating results obtained on Qt1 and the existing chronostratigraphic framework, terrace Qt2 should be younger than Qt1. This would suggest that among the two samples from Qt2, ALC1203 is most likely the one providing the best estimation of the age of Terrace Qt2, with an age result of $842 \pm 149$ ka based on the Al center. The older age obtained for sample ALC1204 might indicate that the sediment have been reworked from older deposits, may be from a remnant from terrace Qt1. However, given the agreement between ESR Al and Ti-Li age estimates for this sample, this reworking must have occurred without exposing the sediment to sunlight, or for such a short time that it has not been recorded by the Ti-Li signal. Actually, the incorporation of sediment coming from remnants of older terraces into younger terraces also has been previously argued by Lewis et al. (2009) to establish the OSL dating chronology of the Upper Pleistocene terraces of the Cinca River sequence.

Consequently, we would consider a weighted mean age of $817 \pm 68$ ka derived from the ESR-Al and $-\mathrm{Ti}-\mathrm{Li}$ age results obtained for ALC1203 as the most reasonable age estimate for the Terrace Qt2 (Fig. 2).

Finally, although Rink et al. (2007) suggested that age consistency between $\mathrm{Al}$ and $\mathrm{Ti}$ centers for a given sample is an evidence for age accuracy, our results obtained from terraces Qt1 and Qt2 do not support this hypothesis. Actually, ESR ages derived from $\mathrm{Al}$ and $\mathrm{Ti}-\mathrm{Li}$ centers for a given sample are not independent ages. They only differ on the $\mathrm{D}_{\mathrm{E}}$ determination and share many sources of uncertainty. Any bias in the stratigraphical positioning of the sample, the sample preparation or dose rate evaluation would actually make both $\mathrm{Al}$ and Ti-ESR ages inaccurate.

\subsection{Geomorphological interpretation of the ESR age results}

The interpretation of our ESR age results indicates that an age of $1276 \pm 104 \mathrm{ka}$ and $817 \pm 68$ ka may be considered for terraces Qt1 and Qt2, respectively (Fig. 2). These are the first numerical ages obtained for these two highest terraces of the Alcanadre River system. These morphosedimentary archives have been mapped and described for a long time (Bomer, 1979; Alberto et al., 1983; Rodríguez-Vidal, 1986; Sancho, 1991). In particular, the complex multi-storey calcrete profiles identified on Qt1 terrace (Sancho and Meléndez, 1992; Meléndez et al., 2011) indicate a high degree of soil development that is in good agreement with the numerical age reported here.

The provided ages record the earliest fluvial sedimentary activity in the Tertiary Ebro basin under exoreic conditions and therefore represent a paleogeographic and geomorphological landmark of high interest in the long-term landscape evolution in the northeastern Iberian Peninsula. Indeed, fluvial downcutting and erosion related processes lasted several million years in the Tertiary Ebro Basin between its opening toward the Mediterranean Sea (13-8.5 Ma ago) (García-Castellanos et al., 2003; Ache et al., 2010; Vázquez-Urbez et al., 2013) and the Alcanadre Qt1 terrace dated here to $\sim 1.3 \mathrm{Ma}$. It is remarkable that these fluvial culminant levels are also recognized in most valleys of the Southern Pyrenean sector of the Ebro Basin (e.g. Noguera Ribagorzana, Cinca and Gállego Rivers). The implications of these first numerical ages obtained in the area on the landscape evolution and other associated 
processes will be further explored in detail in a forthcoming paper by Sancho et al.

At the moment, only some paleomagnetic data have been produced for Early Pleistocene terraces in the Ebro Basin. Besides, these chronological inputs come from fluvial units affected by synsedimentary karstic subsidence in the Gállego River valley (Benito et al., 1998) and the Ebro River valley (Gil et al., 2013). At a larger scale, some palaeomagnetic data from Early Pleistocene terraces have been recently reported in the Iberian Peninsula, for example by Pérez-González et al. (2013) in the Tagus River valley, Benito-Calvo et al. (2008) in the Arlanzón River valley (Duero Basin) and Baena and Díaz del Olmo (1994) in the Guadalquivir River valley. There is, however, a clear lack of numerical ages for these old terraces as highlighted by Silva et al. (2013) and Santisteban and Schulte (2007), which makes virtually impossible any attempt of high resolution correlations between the various basins of the Iberian Peninsula. To our knowledge, only two Early Pleistocene terraces of the Arlanzón River in the Duero Basin provided numerical ages (Moreno et al., 2012): $1.14 \pm 0.13 \mathrm{Ma}$ for the so-called T3 terrace $(+70-78 \mathrm{~m}), 0.93 \pm 0.10 \mathrm{Ma}$ and $0.78 \pm 0.12 \mathrm{Ma}$ for T4 $(60-67 \mathrm{~m})$. However, these ESR age results based on optically bleached quartz grains are derived from the measurement of the Al center only, and should therefore be considered as maximum possible ages. In addition, the Vera Basin (SE Spain) has also yielded several ESR age estimates of > 1.5 Ma (Wenzens, 1992) from travertines. However, as mentioned by Santisteban and Schulte (2007), these results represent "only crude age estimates" (p. 2747), and in absence of a detailed description of the methodology, it is actually impossible to further evaluate the reliability of these ages.

\section{Concluding remarks}

This study presents several ESR ages for the two highest terraces (Qt1 and Qt2) of the Alcanadre River system, providing some insights on the beginning of the Quaternary fluvial morphosedimentary activity in the Ebro Basin in a context of continuous entrenchment of the network. These results are in good agreement with the available loose yet chronostratigraphic framework based on palaeomagnetic data. In the light of these encouraging data, additional ESR samples should be specifically collected in younger terraces as well as in other Quaternary fluvial sequences outcropping in adjacent River valleys, in order to improve the regional chronostratigraphic scenario.

From a methodological point of view, our results show the importance to measure both $\mathrm{Al}$ and $\mathrm{Ti}$ centers for dating purpose, which is so far the best way to have an idea about whether the Al center has been fully bleached or not prior to sediment deposition. Without the measurement of the Ti-center, ESR age estimates based on the Al center alone may by default be considered as maximum possible ages, given the significant uncertainty arising from the slow bleaching kinetics of the signal. First suggested by Toyoda et al. (2000), the use of the MC approach in ESR dating of optically bleach quartz grain appears to be a major improvement for the reliability of the dating method, since both the Al and Ti centers show complementary strengths and weaknesses. At some point, one may reasonably wonder whether the systematic measurement of these two centers in a given sample should not become a standard requirement for the analytical dating procedure in the future. The overall apparent consistency between the ESR age estimates and the existing preliminary chronostratigraphic framework may be considered as an empirical evidence that the $\mathrm{Ti}-\mathrm{Li}$ center may actually work for Early Pleistocene deposits (in agreement with previous observations by Rink et al., 2007), whereas the $\mathrm{Ti}-\mathrm{H}$ center shows some clear limitations instead. Additionally, the age scattering observed in Qt2 illustrates the necessity to rely on more than one sample to get a reliable estimate of the chronology of a given terrace.

Finally, the present work contributes to fill a gap in the chronological framework of the Early Pleistocene terraces of the Ebro basin and to improve the Quaternary stratigraphy of the Iberian Peninsula. The results obtained demonstrate the interest of using ESR dating of optically bleached quartz grains in fluvial context in order to get some numerical ages for the oldest Quaternary fluvial terraces that can usually not be dated by other means.

\section{Acknowledgments}

This study was partially sponsored by the project CGL201016821 from the Spanish Ministry of Science and Innovation. MD has received funding from a Marie Curie International Outgoing Fellowship from the People Programme (Marie Curie Actions) of the European Union's Seventh Framework Programme (FP7/361 2007-2013) under REA grant agreement $n^{\circ}$ PIOF-GA-2013-626474. This is a contribution by PaleoQ Group (Aragón Government and University of Zaragoza). We thank two anonymous reviewers for constructive comments.

\section{Appendix A. Supplementary data}

Supplementary data related to this article can be found at http:// dx.doi.org/10.1016/j.quageo.2015.06.006.

\section{Uncited references}

Duval et al., 2009; Grün, 1989, 1996, 2008; Grün and Rhodes, 1991; Grün and Rhodes, 1992; Guérin et al., 2012; Rodríguez, 1983; Vandenberghe, 2003; Walther and Zilles, 1994; Grün and Brumby, 1994.

\section{References}

Ache, A., Evans, G., Clavell, E., 2010. Some considerations on the initiation of the present SE Ebro River drainage system: post- or pre-Messinian? J. Iber. Geol. 36 (1), 73-85.

Aitken, M.J., 1998. An Introduction to Optical Dating. Oxford University Press, London.

Alberto, F., Gutiérrez, M., Ibáñez, M.J., Machín, J., Meléndez, A., Peña, J.L., Pocoví, A., Rodríguez, J., 1983. El piedemonte Pliocuaternario en el sector central pirenaico (Huesca y Lérida). Geographicalia 18, 109-126.

Arnold, L.J., Duval, M., Falguères, C., Bahain, J.J., Demuro, M., 2012. Portable gamma spectrometry with cerium-doped lanthanum bromide scintillators: suitability assessments for LUMINESCENCE and electron spin resonance dating applications. Radiat. Meas. 47 (1), 6-18.

Arnold, L.J., Demuro, M., Parés, J.M., Pérez-González, A., Arsuaga, J.L., Bermúdez de Castro, J.M., Carbonell, E., 2014. Evaluating the suitability of extended-range luminescence dating techniques over early and Middle Pleistocene timescales: published datasets and case studies from Atapuerca, Spain. Quat. Int. (0)

Asagoe and Toyoda (submitted for publication). ESR dating and dose recovery tests using impurity centers in volcanic quartz. Quat. Geochronol..

Baena, R., Díaz del Olmo, F., 1994. Cuaternario aluvial de la depresión del Guadalquivir: episodios geomorfológicos y cronología paleomagnética. Geogaceta $15,102-104$.

Benito, G., Pérez-González, A., Gutiérrez, F., Machado, M.J., 1998. River response to Quaternary large-scale subsidence due to evaporite solution (Gállego River, Ebro Basin, Spain). Geomorphology 22, 243-263.

Benito-Calvo, A., Pérez-González, A., Parés, J., 2008. Quantitative reconstruction of Late Cenozoic landscapes: a case study in the Sierra de Atapuerca (Burgos, Spain). Earth Surf. Process. Landforms 33, 196-208.

Bomer, B., 1979. Les piedmonts du Bassin de l'Ebre (Espagne). Méditerranée 3. 19-25.

Brennan, B.J., 2003. Beta doses to spherical grains. Radiat. Meas. 37 (4-5), 299-303.

Brennan, B.J., Lyons, R.G., Phillips, S.W., 1991. Attenuation of alpha particle track dose for spherical grains. Int. J. Radiat. Appl. Instrum. Part D. Nucl. Tracks Radiat. Meas. 18 (1-2), 249-253.

Bridgland, D., Westaway, R., 2008. Climatically controlled river terrace staircases: a worldwide quaternary phenomenon. Geomorphology 98 (3-4), 285-315.

Bridgland, D., Maddy, D., Bates, M., 2004. River terrace sequences: templates for quaternary geochronology and marine-terrestrial correlation. J. Quat. Sci. 19 (2), 203-218. 
Burdette, K.E., Rink, W.J., Mallinson, D.J., Means, G.H., Parham, P.R., 2013. Electron spin resonance optical dating of marine, estuarine, and aeolian sediments in Florida, USA. Quat. Res. 79 (1), 66-74.

Calle, M., 2012. Distribución espacio-temporal de las terrazas del río Alcanadre (provincia de Huesca): controles climáticos y/o tectónicos (Master thesis). Universidad de Zaragoza, p. 58.

Calle, M., Sancho, C., Peña, J.L., Cunha, P., Oliva-Urcia, B., Pueyo, E., 2013. La secuencia de terrazas cuaternarias del río Alcanadre (provincia de Huesca) caracterización y consideraciones paleoambientales. Cuad. Investig. Geográfica 39 (1), 159-178.

Cordier, S., Harmand, D., Lauer, T., Voinchet, P., Bahain, J.-J., Frechen, M., 2012 Geochronological reconstruction of the Pleistocene evolution of the Sarre valley (France and Germany) using OSL and ESR dating techniques. Geomorphology (0)

Duval, M., 2012. Dose response curve of the ESR signal of the aluminum center in quartz grains extracted from sediment. Anc. TL 30 (2), 1-9.

Duval, M., 2015. Comments on "ESR dating of the Majuangou and Banshan Paleolithic sites in the Nihewan Basin, North China" by Liu et al. J. Hum. Evol. http:/ dx.doi.org/10.1016/j.jhevol.2015.04.010 (in press).

Duval, M., Guilarte Moreno, V., 2012. Assessing the influence of the cavity temperature on the ESR signal of the aluminum center in quartz grains extracted from sediment. Anc. TL 30 (2), 11-16.

Duval, M., Arnold, L.J., 2013. Field gamma dose-rate assessment in natural sedimentary contexts using $\mathrm{LaBr} 3(\mathrm{Ce})$ and $\mathrm{NaI}(\mathrm{Tl})$ probes: a comparison between the "threshold" and "windows" techniques. Appl. Radiat. Isotopes 74 (0) 36-45.

Duval, M., Guilarte, V., 2015. ESR dosimetry of optically bleached quartz grains extracted from Plio-quaternary sediment: evaluating some key aspects of the ESR signals associated to the Ti-centers. Radiat. Meas. 78 (0), 28-41.

Duval, M., Grün, R., Falguères, C., Bahain, J.J., Dolo, J.M., 2009. ESR dating of lowe pleistocene fossil teeth: limits of the single saturating exponential (SSE) function for the equivalent dose determination. Radiat. Meas. 44 (5-6), 477-482.

Duval, M., Guilarte Moreno, V., Grün, R., 2013. ESR dosimetry of fossil enamel: some comments about measurement precision, long-term signal fading and dose-response curve fitting. Radiat. Prot. Dosim. 157 (4), 463-476.

Duval, M., Bahain, J.-J., Falguères, C., Garcia, J., Guilarte, V., Grün, R., Martínez, K. Moreno, D., Shao, Q., Voinchet, P., 2015. Revisiting the ESR chronology of the early pleistocene hominin occupation at Vallparadís (Barcelona, Spain). Quat. Int. http://dx.doi.org/10.1016/j.quaint.2014.08.054 (in press)

Forman, S.L., Pierson, J., Lepper, K., 2000. Luminescence geochronology. In: Sowers, J., Noller, J., WR, L. (Eds.), Quaternary Geochronology: Methods and Applications. American Geophysical Union, Washington, DC, pp. 157-176.

García-Castellanos, D., Vergés, J., Gaspar-Escribano, J., Cloethingh, S., 2003. Interplay between tectonics, climate, and fluvial transport during the Cenozoic evolution of the Ebro Basin (NE Iberia). J. Geophys. Res. 108 (B7), 2347. ETG 8-1-18.

Gil, H., Pueyo, E., Palma-Rodrígues, A., Soriano, M.A., Luzón, A., Pocoví, A., Pérez, A. Yuste, A., 2013. Caracterización paleomagnética y anisotropía de susceptibilidad magnética (ASM) preliminar de las terrazas antiguas del río Ebro. Geogaceta 53, 129-132.

Grün, R., 1989. Electron spin resonance (ESR) dating. Quat. Int. 1 (0), 65-109.

Grün, R., 1994. A cautionary note: use of 'water content' and 'depth for cosmic ray dose rate' in AGE and DATA programs. Anc. TL 12 (2), 50-51.

Grün, R., 1996. Errors in dose assessment introduced by the use of the "linear part" of a saturating dose response curve. Radiat. Meas. 26 (2), 297-302.

Grün, R., 2008. Editorial. Quat. Geochronol. 3 (1-2), 1

Grün, R., Rhodes, E.J., 1991. On the selection of dose points for saturating exponential ESR/TL dose response curves. Anc. TL 9 (3), 40-46.

Grün, R., Rhodes, E.J., 1992. Simulations of saturating exponential ESR/TL dose response curves - weighting of intensity values by inverse variance. Anc. TL 10 (3), 50-56.

Grün, R., Brumby, S., 1994. The assessment of errors in past radiation doses extrapolated from ESR/TL dose-response data. Radiat. Meas. 23 (2-3), 307-315.

Guérin, G., Mercier, N., Adamiec, G., 2011. Dose-rate conversion factors: update. Anc TL 29 (1), 5-8.

Guérin, G., Mercier, N., Nathan, R., Adamiec, G., Lefrais, Y., 2012. On the use of the infinite matrix assumption and associated concepts: a critical review. Radiat. Meas. 47 (9), 778-785

Hosfield, R.T., Chambers, J.C., 2005. Pleistocene geochronologies for fluvial sedimentary sequences: an archaeologist's perspective. J. Quat. Sci. 20 (3), 285-296.

Ikeya, M., 1993. New Applications of Electron Spin Resonance Dating, Dosimetry and Microscopy. World Scientific, Singapore.

Jain, M., Murray, A.S., Botter-Jensen, L., 2004. Optically stimulated luminescence dating: how significant is incomplete light exposure in fluvial environments? Quaternaire 143-157.

Laurent, M., Falguères, C., Bahain, J.J., Rousseau, L., Van Vliet Lanoé, B., 1998. ESR dating of quartz extracted from quaternary and neogene sediments: method, potential and actual limits. Quat. Sci. Rev. 17 (11), 1057-1062.

Lewis, C.J., McDonald, E.V., Sancho, C., Peña, J.L., Rhodes, E.J., 2009. Climatic implications of correlated Upper Pleistocene glacial and fluvial deposits on the Cinca and Gállego Rivers (NE Spain) based on OSL dating and soil stratigraphy. Glob. Planet. Change 67 (3-4), 141-152.

Martins, A.A., Cunha, P.P., Huot, S., Murray, A.S., Buylaert, J.P., 2009. Geomorphological correlation of the tectonically displaced Tejo River terraces (Gavião-Chamusca area, central Portugal) supported by luminescence dating. Quat. Int. 199 (1-2), 75-91.
Meléndez, A., Alonso-Zarza, A.M., Sancho, C., 2011. Multi-storey calcrete profiles developed during the initial stages of the configuration of the Ebro Basin's exorrheic fluvial network. Geomorphology 134, 232-248.

Mishra, S., White, M.J., Beaumont, P., Antoine, P., Bridgland, D.R., LimondinLozouet, N., Santisteban, J.I., Schreve, D.C., Shaw, A.D., Wenban-Smith, F.F. Westaway, R.W.C., White, T.S., 2007. Fluvial deposits as an archive of early human activity. Quat. Sci. Rev. 26 (22-24), 2996-3016

Moreno, D., Falguères, C., Pérez-González, A., Duval, M., Voinchet, P., BenitoCalvo, A., Ortega, A.I., Bahain, J.-J., Sala, R., Carbonell, E., Bermúdez de Castro, J.M., Arsuaga, J.L., 2012. ESR chronology of alluvial deposits in the Arlanzón valley (Atapuerca, Spain): Contemporaneity with Atapuerca Gran Dolina site. Quat. Geochronol. 10 (0), 418-423.

Pan, B., Burbank, D., Wang, Y., Wu, G., Li, J., Guan, Q., 2003. A 900 k.y. record of strath terrace formation during glacial-interglacial transitions in northwest China. Geology 31 (11), 957-960.

Perez-González, A., Gallardo, J., Uribelarrea, D., Panera, J., Rubio, S., 2013. La inversión Matuyama-Brunhes en la secuencia de terrazas del río Jarama entre Velilla de San Antonio y Altos de la Mejorada, al SE de Madrid (España). Estud. Geológicos 69 (1), 35-46.

Prescott, J.R., Hutton, J.T., 1988. Cosmic ray and gamma ray dosimetry for TL and ESR. Int. J. Radiat.Appl. Instrum. Part D. Nucl. Tracks Radiat. Meas. 14 (1-2), 223-227.

Prescott, J.R., Hutton, J.T., 1994. Cosmic ray contributions to dose rates for luminescence and ESR dating: large depths and long-term time variations. Radiat. Meas. 23 (2-3), 497-500

Preusser, F., Chithambo, M.L., Götte, T., Martini, M., Ramseyer, K., Sendezera, E.J., Susino, G.J., Wintle, A.G., 2009. Quartz as a natural luminescence dosimeter. Earth-Sci. Rev. 97 (1-4), 184-214.

Rink, W.J., Bartoll, J., Schwarcz, H.P., Shane, P., Bar-Yosef, O., 2007. Testing the reliability of ESR dating of optically exposed buried quartz sediments. Radiat. Meas. 42 (10), 1618-1626.

Rodríguez, J., 1983. Geomorfología de las Sierras Exteriores oscenses y su piedemonte. Instituto de Estudios Altoragoneses, Colección de Estudios Altoaragoneses, Huesca, p. 172

Sancho, C., 1991. Geomorfología de la cuenca baja del río Cinca (PhD Thesis). University of Zaragoza, p. 743

Sancho, C., Meléndez, A., 1992. Génesis y significado ambiental de los caliches Pleistocenos de la región del Cinca (Depresión del Ebro). Rev. la Soc. Geológica España 5 (1-2), 81-93.

Sancho, C., Peña, J.L., Lewis, C., McDonald, E., Rhodes, E., Pueyo, E.L., Gosse, J., 2007. Cronología del sistema de terrazas cuaternarias en la cuenca del rio Cinca (Pirineos y depresión del Ebro). In: Proceedings of the XII Reunión Nacional de Cuaternario, Ávila, pp. 31-32.

Santisteban, J.I., Schulte, L., 2007. Fluvial networks of the Iberian Peninsula: a chronological framework. Quat. Sci. Rev. 26 (22-24), 2738-2757.

Schulte, L., Julià, R., Burjachs, F., Hilgers, A., 2008. Middle Pleistocene to Holocene geochronology of the River Aguas terrace sequence (Iberian Peninsula): fluvial response to Mediterranean environmental change. Geomorphology 98 (1-2), $13-33$.

Sharp, W.D., Ludwig, K.R., Chadwick, O.A., Amundson, R., Glaser, L.L., 2003. Dating fluvial terraces by $230 \mathrm{Th} / \mathrm{U}$ on pedogenic carbonate, Wind River Basin, Wyoming. Quat. Res. 59 (2), 139-150.

Silva, P.G., Roquero, E., López-Recio, M., Huerta, P., Tapias, F., 2013. Statistical approach to the chronosequence of fluvial terraces in the Tagus and Duero basins (Central Spain). In: Baena, R., Fernández, J.J., Guerrero, I. (Eds.), El Cuaternario Ibérico: Investigación en el S. XXI, vols. 29-33. VIII Reunión de Cuaternario Ibérico.

Singer, B.S., 2014. A quaternary geomagnetic instability time scale. Quat. Geochronol. 21 (0), 29-52.

Tauxe, L., 2010. Essentials of Paleomagnetism. University of California Press, Berkeley.

Tissoux, H., Falguères, C., Voinchet, P., Toyoda, S., Bahain, J.J., Despriée, J., 2007. Potential use of Ti-center in ESR dating of fluvial sediment. Quat. Geochronol. 2 $(1-4), 367-372$.

Tissoux, H., Toyoda, S., Falguères, F., Voinchet, P., Takada, M., Bahain, J.-J., Despriée, J., 2008. ESR dating of sedimentary quartz from two Pleistocene deposits using Al and Ti-centers. Geochronometria 30, 23-31.

Tissoux, H., Voinchet, P., Lacquement, F., Prognon, F., Moreno, D., Falguères, C., Bahain, J.-J., Toyoda, S., 2012. Investigation on non-optically bleachable components of ESR aluminium signal in quartz. Radiat. Meas. 47 (9), 894-899.

Toyoda, S., Ikeya, M., 1991. Thermal stabilities of paramagnetic defect and impurity centers in quartz: Basis for ESR dating of thermal history. Geochem. J. 25, $437-445$.

Toyoda, S., Falguères, C., 2003. The method to represent the ESR signal intensity of the aluminium hole center in quartz for the purpose of dating. Adv. ESR Appl. 20, 7-10.

Toyoda, S., Voinchet, P., Falguères, C., Dolo, J.M., Laurent, M., 2000. Bleaching of ESR signals by the sunlight: a laboratory experiment for establishing the ESR dating of sediments. Appl. Radiat. Isotopes 52 (5), 1357-1362.

Vandenberghe, D., De Corte, F., Buylaert, J.P., Kučera, J., Van den haute, P., 2008. On the internal radioactivity in quartz. Radiat. Meas. 43 (2-6), 771-775.

Vandenberghe, J., 2003. Climate forcing of fluvial system development: an evolution of ideas. Quat Sci. Rev. 22 (20), 2053-2060.

Vázquez-Urbez, M., Arenas, C., Pardo, G., Pérez-Rivarés, J., 2013. The effect of drainage reorganization and climate on the sedimentologic evolution of 
intermontane lake systems: the final fill stage of the Tertiary Ebro Basin (Spain). J. Sediment. Res. 83, 562-590.

Voinchet, P., Falguères, C., Laurent, M., Toyoda, S., Bahain, J.J., Dolo, J.M., 2003. Artificial optical bleaching of the aluminium center in quartz implications to ESR dating of sediments. Quat. Sci. Rev. 22 (10-13), 1335-1338.

Voinchet, P., Falguères, C., Tissoux, H., Bahain, J.-J., Despriée, J., Pirouelle, F., 2007. ESR dating of fluvial quartz: estimate of the minimal distance transport required for getting a maximum optical bleaching. Quat. Geochronol. 2 (1-4), 363-366.

Voinchet, P., Despriée, J., Tissoux, H., Falguères, C., Bahain, J.J., Gageonnet, R., Dépont, J., Dolo, J.M., 2010. ESR chronology of alluvial deposits and first human settlements of the Middle Loire Basin (Region Centre, France). Quat. Geochronol. 5 (2-3), 381-384.
Walther, R., Zilles, D., 1994. ESR studies on flint with a difference-spectrum method. Quat. Sci. Rev. 13 (5-7), 635-639.

Wegmann, K.W., Pazzaglia, F.J., 2009. Late Quaternary fluvial terraces of the Romagna and Marche Apennines, Italy: climatic, lithologic, and tectonic controls on terrace genesis in an active orogen. Quat. Sci. Rev. 28 (1-2), 137-165.

Wenzens, G, 1992. The influence of tectonics and climate on the Villafranchian morphogenesis in semiarid Southweastern Spain. Z. Geomorph. N. F. 84 (Suppl. Bd), 173-184.

Westaway, R., Bridgland, D.R., Sinha, R., Demir, T., 2009. Fluvial sequences as evidence for landscape and climatic evolution in the Late Cenozoic: a synthesis of data from IGCP 518. Glob. Planet. Change 68 (4), 237-253.

Yokoyama, Y., Falgueres, C., Quaegebeur, J.P., 1985. ESR dating of quartz from quaternary sediments: first attempt. Nucl. Tracks Radiat. Meas. 10 (4-6), 921-928. 